\title{
A PÓS-MODERNIDADE E O PATRIMÔNIO CULTURAL EDIFICADO: QUESTÕES CONTEMPORÂNEAS E SEU IMPACTO NA FORMAÇÃO DO CIDADÃO*
}

\author{
Priscila Henning ${ }^{1}$
}

\begin{abstract}
Resumo:
O artigo propõe uma análise do processo de expansão do conceito do patrimônio cultural ao longo dos séculos XX e XXI, com especial ênfase no contexto histórico-cultural da contemporaneidade. Neste período, diversos autores identificam uma condição sociocultural e estética específica que rompe com os paradigmas da modernidade, caracterizada como pós-modernidade ou outros termos com sentidos similares. O campo disciplinar da arquitetura e urbanismo foi, conforme afirmam Jameson (1997) e Harvey (2008), um dos primeiros a perceber esta ruptura e as especificidades desta nova lógica cultural se faz sentir nas construções e nas cidades, inclusive nas tradicionais, reconhecidas como patrimônio. O campo específico do patrimônio cultural experimentou, nas últimas décadas, um acelerado processo de expansão tanto conceitual e de suas categorias, como também do seu recorte geográfico e temporal. Ferramenta essencial para a construção da cidadania, da educação cultural e cívica e da consciência coletiva, o patrimônio cultural parece experimentar, no último século, um reconhecimento sem precedentes. No entanto, por ser um acurado espelho da sociedade, as questões e tensões demonstradas pelo patrimônio cultural nas últimas décadas também refletem disputas: contestações e ressignificações de memórias e monumentos, confrontando as grandes metanarrativas totalizantes e universais da modernidade, em prol da construção de um discurso mais complexo, representativo, inclusivo e diversos. Outra questão que impacta o processo contemporâneo de patrimonialização é a comoditização da cultura e da memória, que passa a ser consumida e gerida pela indústria turística, sofrendo os efeitos típicos da sociedade do espetáculo que Débord (1997) descreve e que parece se consolidar cada vez mais, agora com o auxílio das tecnologias digitais. Com base neste quadro, questiona-se qual é o impacto destas questões na construção do cidadão contemporâneo, diante das complexidades, contradições e disputas narrativas, e quais seriam os desafios da educação patrimonial?
\end{abstract}

Palavras-chave: Patrimônio cultural. Pós-modernidade. Contemporaneidade. Cidadania.

\section{POST-MODERNITY AND BUILT CULTURAL HERITAGE: CONTEMPORARY ISSUES AND THEIR IMPACT ON THE FORMATION OF CITIZENSHIP}

\begin{abstract}
:
This article proposes to analyze the expansion process of the concept of cultural heritage throughout the 20th and 21 st centuries, with special emphasis on contemporary historic-cultural context. In this period, several authors identified a specific sociocultural and aesthetic condition that breaches the paradigms of modernity, characterized as post-modernity or other terms with similar meanings. The disciplinary field of Architecture and Urbanism was, according do Jameson (1997) and Harvey (2008), one of the first to perceive this rupture - and the specificities of this new cultural logic can be felt in buildings and cities, including the traditional sites classified as cultural heritage. The specific field of cultural heritage conservation has experienced, in the past decades, an accelerated expansion process of its concepts and categories, as well as its temporal and geographic approach. Cultural heritage is viewed as an essential tool for building cultural and civic education, citizenship and collective conscience, and

\footnotetext{
${ }^{*}$ Trabalho decorrente da tese de doutorado defendida na Universidade Estadual de Campinas em 2019, com auxílio e fomento do CNPq.

${ }^{1}$ Graduada em Arquitetura e Urbanismo pela Universidade Estadual de Londrina (2002); com especialização em História e Teorias da Arte: Modernidade e Pós-Modernidade pela Universidade Estadual de Londrina (2003); mestre em Arquitetura e Urbanismo pela Universidade de São Paulo (2007); e doutora em História pela Universidade Estadual de Campinas (2019). Docente dos Cursos de Arquitetura e Urbanismo da Universidade Pitágoras Unopar e Universidade Positivo em Londrina/PR. É membro do Conselho Municipal de Preservação do Patrimônio Cultural (COMPAC) da cidade de Londrina desde 2018. Membro do GP Filosofia, educação e condição humana. E-mail para contato: prihenning @yahoo.com.
} 
has experienced, in the past century, an unprecedented recognition. However, due to its role as an accurate mirror of society, the questions and tensions demonstrated by cultural heritage in the past few decades also reveal disputes: challenges and redefinitions pf memories and monuments, confronting the great totalizing and universal metanarratives of modernity, on behalf of building a more complex, representative, inclusive and diverse discourse. Another question that impacts the contemporary process of heritageization is the commodification of memory and culture, now consumed and managed by the touristic industry, and suffering the typical effects of the society of spectacle that Débord (1997) described and that seems to consolidate itself more and more, with the aid of digital technologies. Based on this framework, we question what is the impact of these issues in the building of the contemporary citizen, in face of the complexities, contradictions and narrative disputes, and what would be the challenges of heritage education?

Keywords: Cultural heritage. Post-modernity. Contemporaneity. Citizenship.

As discussões sobre o pós-modernismo², no campo da arquitetura e do urbanismo, costumam ser associadas a críticas, manifestos e rupturas que se intensificam sobretudo a partir das décadas de 1960 e 1970, com a percepção da superação do movimento moderno como paradigma da concepção do espaço privado ou coletivo ideal. Neste período, a partir do contexto de reconstrução das cidades europeias após o término da Segunda Guerra Mundial e das profundas mudanças nos modos de vida na segunda metade do século XX, as limitações e até mesmo o fracasso dos ideais modernistas preconizados por autores como Le Corbusier e o movimento arquitetônico que se consolidou como "Estilo Internacional"3 foram simbolizados, sobretudo, pela demolição do conjunto habitacional Pruitt-Igoe em Saint Louis, EUA, em 1972 - evento este tornado notório pelo polêmico crítico da arquitetura Charles Jencks como "o dia em que o movimento moderno morreu" em sua obra A linguagem da arquitetura pós-moderna, publicado originalmente em 1977. Segundo Jameson,

é no âmbito da arquitetura que as modificações da produção estética são mais dramaticamente evidentes e seus problemas teóricos têm sido mais consistentemente abordados e articulados (...) de modo mais decisivo que nas outras artes ou na mídia,

\footnotetext{
${ }^{2}$ Há divergências quanto à definição e conceituação dos termos pós-modernismo e pós-modernidade, não entendidos como sinônimos. Para fins deste texto, serão adotados pós-modernidade como a designação da do contexto histórico de rupturas em diversos âmbitos (culturais, sociais, filosóficos, econômicos) e sua condição social a partir do pós-guerra, como uma nova temporalidade que sucede a modernidade; enquanto que pósmodernismo, aqui, se refere às postulações teóricas de correntes específicas no campo das artes, da cultura e da filosofia.

3 O chamado "Estilo Internacional" (International Style) foi uma linguagem arquitetônica característica do modernismo em arquitetura e urbanismo, divulgada sobretudo nos Congressos Internacionais de Arquitetura Moderna (CIAMs), realizados entre 1928 e 1956. O moderno era uma causa que transformaria o modo de viver da humanidade, adaptando-a à era da máquina, rompendo radicalmente com a arquitetura de inspiração historicista e pela concepção tradicional das cidades, consideradas obsoletas e pouco funcionais. Enfatiza o uso do racionalismo na concepção e organização dos espaços, abolindo toda ornamentação supérflua e utilizava materiais construtivos inovadores, como concreto, vidro industrial e estruturas metálica. Nas cidades, propunham grandes projetos que organizavam e separavam as funções da cidade e uniformizavam tipologias construtivas autorreferentes, sem concessões às preexistências. Dentre os principais arquitetos do movimento, se destacam Le Corbusier, Walter Gropius e a Bauhaus, Mies van der Rohe e Philip Johnson, entre outros. No Brasil, as ideias de Le Corbusier influenciaram várias gerações de arquitetos brasileiros, como a Escola Carioca (que tem Oscar Niemeyer e Lucio Costa como principais representantes) e a Paulista, com nomes como Vilanova Artigas e Paulo Mendes da Rocha. Ver: HARVEY, 2008; FRAMPTON, 2004.
}

\begin{tabular}{|c|c|c|c|c|}
\hline Qovista Dialectus & Ano 10 & n. 22 & Edição Especial, junho 2021 & p. 64- 83 \\
\hline
\end{tabular}


na arquitetura as posições pós-modernistas são inseparáveis de uma crítica implacável ao alto modernismo arquitetônico (JAMESON, 1997, p. 28).

O conceito de pós-modernismo se origina, portanto, da crítica no campo das artes e em especial da arquitetura, e apenas depois de se consolidar nestas áreas, migra para as ciências humanas, em um movimento inverso ao que havia acontecido anteriormente com o modernismo (GALLO, 2006, p. 556). Uma hipótese para isto é que o espaço construído das cidades, seus logradouros públicos e seus edifícios, como locus social, é especialmente sensível às mudanças nem sempre evidentes da sociedade, e exibe, de modo tangível, a marca das desigualdades, das disputas e da insuficiência. Através das construções de propostas ousadas e inovadoras ou da demolição ou abandono daquilo que se considera superado, das marcas de violência (buracos de bala nas paredes, pixo e palavras de ordem rabiscados nos muros, monumentos colocados ou derrubados, edifícios incendiados, vandalismo), dos contrastes entre a qualidade e a infraestrutura presente nas áreas "nobres" da cidade e a precariedade dos bairros marginalizados da periferia, da presença da publicidade por todos os cantos, das ocupações e remoções, da dificuldade de mobilidade urbana, dos edifícios e monumentos que se impõem e representam o poder, a cidade é palco do espetáculo social.

As construções e espaços que constituem o patrimônio cultural edificado demonstram estas tensões e relações com especial clareza. O patrimônio, palavra cuja etimologia remete às relações familiares de herança e valor, é um conceito-nômade que, acompanhado pelo adjetivo "cultural", designa a atribuição de um valor excepcional do ponto de vista da cultura de uma dada sociedade (CHOAY, 2001). Os edifícios foram construídos em determinados momentos, e alguns permaneceram enquanto outros foram sendo substituídos, em função das demandas de cada época. Uma vez selecionados e protegidos legalmente, adquirem um status de legitimidade e excepcionalidade. Logo, as dinâmicas de sua natureza, características físicas e os diversos valores atribuídos a eles ao longo do tempo revelam informações importantes da sociedade de cada momento ao longo desta trajetória ${ }^{4}$. O que era a construção originalmente, e pertenceu a quem? Por qual motivo este edifício foi poupado das transformações intrínsecas às cidades? Quando ele passa a ser considerado um objeto de valor cultural? Se protegido legalmente, qual a justificativa para isso, e por quem ou em qual momento este edifício foi selecionado? Ao longo da breve história do campo disciplinar específico do patrimônio cultural, estas questões sempre pautaram o debate e revelam

\footnotetext{
${ }^{4}$ Sobre os valores atribuídos aos bens patrimoniais e as distinções entre monumento e monumento histórico, ver também RIEGL, Alois. O culto moderno dos monumentos: a sua essência e a sua origem. São Paulo: Perspectiva, 2014
}

\begin{tabular}{|c|c|c|c|c|}
\hline Rovista Dialectus & Ano 10 & n. 22 & Edição Especial, junho 2021 & p. 64- 83 \\
\hline
\end{tabular}


dinâmicas sociais e interpretações distintas da identidade nacional, das narrativas históricas adotadas, das memórias e práticas culturais preservadas - ou apagadas, e dos atores que participam destes processos.

A noção de monumento histórico é, por si, uma invenção moderna e reflete uma tensão em si mesma: ao mesmo tempo confiante em um ideal de progresso e futuro, a consciência de ocupar um lugar histórico, transitório, desperta o cuidado com a conservação do legado cultural de períodos anteriores. Apesar dos monumentos ${ }^{5}$ serem erigidos pelas civilizações humanas desde a pré-história, é a partir da Modernidade, sobretudo na conjuntura das transformações e destruições provocadas pelas Revoluções Francesa e Industrial, que se consolidam como objetos de valor cultural que devem ser salvaguardados, tutelados por legislação própria e transmitidos às gerações futuras. Compreendidas como vestígios físicos do passado, estas construções atestavam a presença dos heroicos antepassados naquele território e reforçavam a história como magistra vitae $e^{6}$ que assume um papel educativo como "mestre da vida" (HARTOG, 2014). Os monumentos foram considerados, portanto, no contexto da formação dos Estados Nacionais nos séculos XVIII e XIX, e em especial na França pósrevolucionária, como ferramentas educativas para o patriotismo por meio de uma "pedagogia geral do civismo: os cidadãos estão dotados de uma memória histórica que representará o papel afetivo de uma memória afetiva desde que mobilizada pelo sentimento de orgulho e superioridade nacionais" (CHOAY, 2001, p. 98). No Brasil, já no século XX, o processo foi similar: quando da constituição do então SPHAN (Serviço do Patrimônio Histórico e Artístico $\mathrm{Nacional}^{7}$ ), a maior parte dos bens selecionados como patrimônio eram aqueles pertinentes às grandes metanarrativas da construção da identidade nacional. O patrimônio atua, portanto, como um espelho da sociedade: reflete seus valores, seus ideais, suas tensões, sua visão de si mesmo e de seu passado. "Patrimonializados, [os bens de interesse coletivo] se tornavam um

\footnotetext{
${ }^{5}$ Monumento é uma palavra de origem latina, derivada do verbo monere, que tem como significado "lembrar" ou "advertir". Erigidos desde a pré-história, os monumentos são estruturas que têm como principal função ser suporte da memória, demarcando locais sagrados ou sepulcros, homenageando personagens políticas e religiosas ou episódios da história. A partir do Renascimento italiano, porém, nasce o "monumento histórico", que é o reconhecimento posterior de edificações e estruturas urbanas como dotadas de valor cultural, que não havia sido construída, especificamente, para esta finalidade. O monumento histórico se consolida, se amplia e se ampara em teoria e legislação própria a partir do séc. XVIII, no contexto da formação dos Estados Nacionais (CHOAY, 2001).

${ }^{6}$ Do conceito historia magistra vitae, de Cícero, que presume que o passado, pleno de exemplos, explica claramente o presente e oferece condições de prever o futuro, visto que as experiências do homem repetem-se ao longo do tempo, como se circunscritas em um círculo (HARTOG, 2014, pp. 102-108).

${ }^{7} \mathrm{O}$ órgão nacional de proteção ao patrimônio cultural, IPHAN (Instituto do Patrimônio Histórico e Artístico Nacional), então SPHAN, foi criado pela lei 378/1937. Ao longo das últimas décadas, passou por uma série de mudanças estruturais e de nomenclatura, passando a ser IPHAN desde 1994.
}

\begin{tabular}{|c|c|c|c|c|}
\hline Q Ronista Dialectus & Ano 10 & n. 22 & Edição Especial, junho 2021 & p. 64- 83 \\
\hline
\end{tabular}


conjunto de grande alcance político, a memória da nação, criando simbolicamente a ideia de herança comum a todos, o que fortalecia a unidade nacional" (RODRIGUES, 2020, p. 88).

Deste modo, as transformações sociais e culturais que se estabelecem a partir da segunda metade do século XX se fazem sentir também no patrimônio cultural e no modo com que a sociedade se relaciona com suas manifestações. Embora o patrimônio arquitetônico, por definição, se mantenha pouco alterado ao longo do tempo, o mesmo não ocorre com os valores, significados e funções que são atribuídas a ele. No caso específico das mudanças culturais e sociais que se estabelecem a partir da segunda metade do século XX e que diversos autores conceituam com uma miríade de terminologias distintas ${ }^{8}$, podemos elencar alguns elementos próprios da pós-modernidade que impactaram o campo específico do patrimônio cultural e que, por consequência, revelam mudanças na percepção da identidade, memória, sociedade e até mesmo em categorias como espaço e tempo.

\section{Pós-modernidade: um breve panorama}

As mudanças acarretadas pela passagem do capitalismo industrial para o capitalismo financeiro globalizado no pós-guerra, e o advento do neoliberalismo a partir da década de 1980, alterou profundamente o modo com que a humanidade se relaciona com sua cultura, suas tradições, seu espaço e com seus iguais. O período é marcado, para muitos autores, por um forte individualismo, ou mesmo um hiperindividualismo (LIPOVETSKY, 2004) uma condição em que "a liberdade individual reina soberana: é o valor pelo qual todos os outros valores vieram a ser avaliados e a referência pela qual a sabedoria acerca de todas as normas e resoluções supraindividuais devem ser medidas" (BAUMAN, 1998, p. 9). O consumo e a comunicação de massa pervadem todas as instâncias da vida, fomentando desejos e frustrações, exacerbando as exclusões e comoditizando quase tudo - dos corpos aos espaços, da cultura às causas sociais. Ao mesmo tempo, os questionamentos insurgentes subvertem antigas estruturas que se pretendiam universais, o que leva à fragmentação da experiência e à pluralidade de leituras e narrativas. As metanarrativas totalizantes, que estruturaram a sociedade durante séculos, são contestadas, vistas com desconfiança e até mesmo deslegitimadas (LYOTARD, 2009), seja por meio da relativização, do confronto, do deboche ou da desilusão. Nada é tão

\footnotetext{
${ }^{8}$ Entre os muitos termos que se referem a esta época peculiar de nossa história humana: destacamos pósmodernidade (Lyotard, 1979; Jameson, 1989; Harvey, 1989; Jencks, 1977); hipermodernidade (Lipovetsky, 2004); supermodernidade (Augé, 1992); modernidade líquida (Bauman, 1999); modernidade tardia (Giddens, 1991), até mesmo à manutenção do próprio termo modernidade (Habermas, 1985), entendido como um projeto ainda inacabado. Embora existam ainda outros autores, estes exemplos são ilustrativos da multiplicidade de acepções.
}

\begin{tabular}{|c|c|c|c|c|}
\hline Qevista Dialectus & Ano 10 & n. 22 & Edição Especial, junho 2021 & p. 64- 83 \\
\hline
\end{tabular}


simples e universal como havia sido prometido pelos ideólogos do moderno, e os projetos de progresso e evolução postos em prática parecem ter resultado, cada vez mais, em uma realidade distópica.

A globalização e a tecnologia reduziram as distâncias e transformaram profundamente as relações do ser humano com categorias básicas como o tempo e o espaço, resultando no fenômeno que David Harvey (2008) denomina de compressão tempo-espaço. A aceleração do tempo no giro do capital (entre produção, consumo e descarte) impactaram na nossa percepção temporal, alterando as condições em que percebemos o transcurso do tempo no capitalismo, resultando na produção de bens e cultura cada vez mais efêmeros e volatilizados. Ao mesmo tempo, a realidade do espaço também se subverte com a globalização aliada às novas tecnologias de comunicação e deslocamento, as quais reduziram as distâncias e o tempo necessário para percorrê-las. A internet e a telefonia móvel, para John Urry, transformaram irreversivelmente diversos padrões de comportamento: "a década de 1990 (...) testemunhou uma notável 'compressão espaço-temporal' à medida que as pessoas, ao redor do globo, se 'aproximaram' por meio dos diversos desenvolvimentos tecnológicos. Para muitos grupos sociais, há, cada vez mais, uma 'morte da distância"” (URRY, 2016). Assim, cada vez mais temos contato com culturas distantes, seja através do deslocamento físico facilitado - o que fez com que a indústria turística crescesse em ritmo exponencial nas últimas cinco décadas, segundo dados anuais compilados pela Organização Mundial do Turismo (OMT), órgão ligado às Nações Unidas; ou seja por meio do acesso em tempo real às imagens e notícias de lugares longínquos por meio da televisão ou da internet (HARVEY, 2008). Este contato com as múltiplas realidades potencializa a fragmentação dos discursos universalistas, uma vez que cada vez mais é possível ter contato com realidades e culturas distintas, resultando em outra característica pós-moderna: a pluralidade e o multiculturalismo, em detrimento dos esquemas universais modernos tidos, neste contexto, como opressivos e monótonos.

Quanto à percepção acelerada do tempo nas últimas décadas, François Hartog introduz a noção de presentismo, um neologismo criado para contrapor-se ao já estabelecido futurismo. A ideia de presentismo é uma forma de entender o presente onipresente, o presente único, "a tirania do instante" (HARTOG, 2014, p. 11), que o autor percebe dominando nossa cultura mais fortemente no século passado, embora mais aprofundada a partir da queda do muro de Berlim em 1989. Hartog afirma: "O século XX aliou, finalmente, futurismo e presentismo. Se, em primeiro lugar, ele foi mais futurista que presentista, terminou mais presentista que 
futurista" (HARTOG, 2014, p. 140). Fredric Jameson (1997), neste sentido, postula que há uma crise de historicidade provocada pelo fato de que o tempo e a temporalidade estão imersos em uma cultura cada vez mais dominada pelo espaço, pela lógica espacial e pelas imagens (JAMESON, 1997, p. 52). Nas produções culturais da cultura popular na pós-modernidade, como filmes, livros e séries, a representação de espaços ou personagens é inspirada em uma visão estilizada e idealizada do passado, tratado de modo meramente formal e superficial. $\mathrm{Na}$ arquitetura pós-moderna, por exemplo, isso é perceptivo nas recriações de espaços inspirados no passado - seja numa arquitetura abertamente historicista (em que elementos próprios de estilos arquitetônicos do passado são retomados e inseridos em edifícios contemporâneos, muitas vezes de modo pouco coerentes com o contexto ou com sua razão de ser) ou em espaços comerciais temáticos que remetem a espaços antigos de modo lúdico e meramente decorativo, como hamburguerias que remetem aos diners americanos ou outros restaurantes de gastronomia estrangeira. Para Jameson (1997, pp. 44-45), este conceito ingênuo de "historicismo" na sociedade pós-moderna leva a um pastiche onipresente, à cultura do simulacro. De forma análoga, Huyssen menciona a "a presente recodificação do passado" (2000, p. 10), afirmando que "nós estamos obcecados com re-representação, repetição, replicação e com a cultura da cópia, com ou sem o original” (HUYSSEN, 2000, p. 24).

O que nos leva a outra questão própria da condição pós-moderna: a própria realidade das imagens é posta em xeque, à medida em que seu simulacro se sobrepõe a ela cada vez mais. Baudrillard (1991), a respeito da natureza da simulação, destaca as fases sucessivas da imagem: primeiro, ela atua como um reflexo de uma realidade profunda. Em seguida, mascara e deforma esta realidade ou a ausência dela. Por fim, ela "não tem qualquer relação com qualquer realidade: ela é o seu próprio simulacro puro" (BAUDRILLARD, 1991, p. 13). As imagens de propaganda, que inicialmente se concentravam em vender produtos exibindo sua aparência atraente (a qual frequentemente é distante da realidade), atualmente, se estendem à manipulação do próprio ser, exibido e vendido pelas redes sociais. O fenômeno de sobreposição do simulacro - a imagem idealizada - sobre o objeto real suscita discussões recentes sobre a não-aceitação da própria imagem sem a manipulação e o aprimoramento possibilitado pelos recursos digitais das redes sociais, potencializando uma procura exacerbada por cirurgias plásticas para adequar a realidade à idealização. Guy Débord, de forma similar, define que esta é a essência da sociedade do espetáculo, onde "a afirmação da aparência e a afirmação de toda vida humana - isto é, social - como simples aparência" (DÉBORD, 1997, p.16). Ou seja, a imagem se destaca do objeto, que adquire primazia sobre o objeto real - as

\begin{tabular}{|c|c|c|c|c|}
\hline Qevista Dialectus & Ano 10 & n. 22 & Edição Especial, junho 2021 & p. 64- 83 \\
\hline
\end{tabular}


relações com as pessoas (e entre elas) passam a se dar através destas imagens, em detrimento do objeto real.

\footnotetext{
O espetáculo apresenta-se ao mesmo tempo como a própria sociedade, como uma parte da sociedade e como instrumento de unificação. Como parte da sociedade, ele é expressamente o setor que concentra todo olhar e toda consciência. Pelo fato deste setor estar separado, ele é o lugar do olhar iludido e da falsa consciência (DÉBORD, 1997, p.14).
}

Aliados à revolução tecnológica e o advento da internet e da virtualidade, entre outras características da vida social nas últimas décadas do século $\mathrm{XX}$, essas complexidades e contradições próprias deste momento histórico tiveram impacto tal que alguns autores argumentam que não há como negar uma ruptura com o projeto moderno, o que indica a necessidade de nomear uma nova fase (HARVEY, 1992; JAMESON, 1997; BAUMAN, 1998). Apesar das discordâncias entre os autores contemporâneos, que divergem sobre terminologias, limites e críticas a esta condição, percebe-se a mudança de paradigma que pode indicar algo novo, ou uma simples radicalização do moderno, que não se conclui (LIPOVETSKY, 2004). Em síntese, a condição pós-moderna aponta a crise ou o fim de estruturas sólidas que organizavam a vida social e a crescente desmaterialização, que vai do dinheiro (no capitalismo financeiro, sem lastro) ao tempo e espaço, as relações sociais, o trabalho, até mesmo a noções como verdade e realidade. $\mathrm{Ou}$, como Bauman $(2001$, p.10) apontou, aquilo que o Manifesto Comunista, ainda em 1848, descrevia como "tudo o que era sólido se desmancha no ar", indicando que o abalo das estruturas tradicionais já ocorria.

A consciência corrente de que "algo se perde" com grande velocidade pode designar, em certa medida, um sentimento de desorientação e insegurança em um mundo cada vez mais instável, em que as mudanças são rápidas e drásticas em todos os setores - na economia, nas estruturas sociais tradicionais, na cultura, na política, na tecnologia, entre tantos outros - e produzem um sentimento de desamparo. Há uma percepção generalizada da possível e iminente destruição de manifestações de determinadas culturas e/ou também de seu passado, das democracias, da clareza entre verdade e mentira, bem como da possibilidade de esgotamento dos recursos naturais, o que provoca um sentimento de urgência em conservar vestígios de uma civilização que parece se desmoronar. Essa sensação também é exacerbada, como Harvey (2008) aponta, como um meio de resistir à padronização e massificação provocada pela globalização econômica, que levanta um paradoxo: ao mesmo tempo em que permite um contato cada vez maior com o outro, também massifica estas relações por imposição do capital. Pode-se afirmar que as ações de preservação tanto cultural quanto ambiental acabam

\begin{tabular}{|c|c|c|c|c|}
\hline Qevista Dialectus & Ano 10 & n. 22 & Edição Especial, junho 2021 & p. 64- 83 \\
\hline
\end{tabular}


se tornando meios de resistência ao ímpeto desenvolvimentista, imediatista e voraz que se mostra cada vez mais destrutivo.

\section{Patrimonialização e pós-modernidade: entrelaçamentos}

É neste contexto de análise que podemos, por uma perspectiva, situar o papel e a natureza do fenômeno da patrimonialização, ou o crescimento e a expansão das categorias de bens considerados de valor cultural e sua apropriação pela sociedade. O termo "patrimônio cultural” é uma acepção contemporânea que compreende diversas manifestações que vão dos bens físicos às manifestações imateriais (tais como folclore ou festas populares, por exemplo), e sua inserção no meio ambiente, porém, no princípio, esta noção estava atrelada quase que exclusivamente aos bens materiais, em especial ao patrimônio arquitetônico do monumento isolado 9 . Ao longo do século XX, sobretudo na segunda metade, o conceito de patrimônio se fragmentou em diversas categorias ${ }^{10}$, contemplando um vasto escopo de atuação: do patrimônio cultural material dos edifícios e conjuntos urbanos, o patrimônio imaterial dos saberes e práticas culturais e modos de vida, o patrimônio natural (em uma conjunção com os movimentos ecológicos), e, por fim, uma associação de todas estas manifestações entrelaçadas, na categoria da paisagem cultural (instituída pelo IPHAN em uma portaria de 2009). Há, ainda, inúmeras classificações e subdivisões de cada uma destas categorias, ressaltando as particularidades e demandas próprias de cada tipo de patrimônio, que requerem abordagens diferenciadas. $\mathrm{Ou}$ seja, nos últimos anos, o conceito se ampliou para várias escalas de espaço, abrange diversas formas de expressão cultural e se manifesta nas diversas temporalidades, cada vez mais próximas do presente.

A popularização e ubiquidade do patrimônio cultural é sintomática, e expressa uma condição particular e mais abrangente da sociedade contemporânea que, de forma massiva, produz e consome vestígios e referências ao passado em suas mais diversas manifestações. Afinal, o processo de patrimonalização vem acompanhando o contexto contemporâneo da pósmodernidade quase dentro do mesmo recorte temporal e, inevitavelmente, sofre seus impactos. Andreas Huyssen, conceituando o que ele denominou de "cultura da memória” (2000), descreve este contexto:

\footnotetext{
9 O patrimônio arquitetônico é uma categoria do patrimônio cultural que abrange os edifícios isolados, conjuntos arquitetônicos e sítios urbanos considerados como detentores de valores culturais.

${ }^{10}$ Para conhecer mais categorias e subdivisões do conceito, ver CARVALHO, Aline; MENEGUELLO,

Cristina. Dicionário Temático do Patrimônio. Campinas: Editora da Unicamp, 2020.
}

\begin{tabular}{|c|c|c|c|c|}
\hline Rovista Dialeatus & Ano 10 & n. 22 & Edição Especial, junho 2021 & p. 64- 83 \\
\hline
\end{tabular}


Desde a década de 1970, pode-se observar, na Europa e nos Estados Unidos, a restauração historicizante de velhos centros urbanos, cidades-museus e paisagens inteiras, empreendimentos patrimoniais e heranças nacionais, a onda da nova arquitetura de museus (que não mostra sinais de esgotamento), o boom das modas retrô e utensílios reprô, a comercialização em massa da nostalgia, a obsessiva automusealização através da câmera de vídeo, a literatura memorialística e confessional, o crescimento dos romances autobiográficos e históricos pós-modernos (com suas difíceis negociações entre fato e ficção), a difusão das práticas memorialísticas nas artes visuais, geralmente usando a fotografia como suporte, e o aumento do número de documentários na televisão, incluindo, nos Estados Unidos, um canal totalmente voltado para história: o History Channel (HUYSSEN, 2000, p. 14).

Dentro desta conjuntura, os monumentos e as cidades históricas vêm ganhando cada vez mais relevância, sobretudo por conta dos deslocamentos de visitantes interessados em turismo cultural, fenômeno que não mostrava sinais de arrefecimento ${ }^{11}$ - ao menos até março de 2020, antes da decretação da pandemia de Covid-19 pela Organização Mundial de Saúde (OMS). O patrimônio recebe investimentos expressivos em programas de revitalização de grande porte, como o Programa Monumenta (1996-2010), no Brasil, que destinou vultosos recursos - via parceria entre o Ministério da Cultura (MinC/IPHAN) e o Banco Interamericano de Desenvolvimento (BID) à recuperação de 26 municípios históricos no Brasil, associando ações de restauração dos imóveis com planejamento estratégico. Em muitos casos, os grandes projetos urbanos aliados às ações de revitalização de regiões antes degradadas (a exemplo das intervenções em regiões portuárias de Barcelona, Buenos Aires e Rio de Janeiro, nos últimos trinta anos) são exemplos de atuações espetacularizadas, visando à valorização econômica dos espaços e à promoção da cidade por meio do marketing urbano, atraindo investimentos e visitantes oriundos do mundo todo (JACQUES, 2003). O patrimônio, portanto, adquire um status não apenas cultural, mas econômico, sendo que este último muitas vezes determina os encaminhamentos a serem adotados e se sobrepõe ao valor cultural, tornando-se um exemplo expressivo da comoditização da cultura nas últimas décadas. As consequências destas atuações são contraditórias: por um lado, como o mais puro espetáculo, na acepção de Débord (1997), imagem reificada da propaganda se estabelece como o próprio objeto, em detrimento das particularidades do local, de sua história e de suas tensões sociais, uma vez que uma consequência frequente destas intervenções é a gentrificação do local e a exclusão de parte da população das regiões impactadas pela intervenção.

A preservação do patrimônio cultural vem se consolidando como campo específico e autônomo do conhecimento desde o século XIX, portanto, relativamente

${ }^{11}$ Para consultar os dados estatísticos e resultados econômicos divulgados a cada ano pela Organização Mundial do Turismo, basta acessar o portal da entidade em: https://www.e-unwto.org/. Acesso em junho de 2021.

\begin{tabular}{|l|l|l|l|l|}
\hline Q Rovista Dialectus & Ano 10 & n. 22 & Edição Especial, junho 2021 & p. 64- 83 \\
\hline
\end{tabular}


recentemente (KÜHL, 2008). A partir de ativa mobilização de intelectuais e de parte da população em prol da defesa dos bens culturais materiais em risco de destruição no âmbito das Revoluções Francesa e Industrial, foram, por fim, consolidadas as primeiras ações que conformaram um novo campo de saber, com especificidade técnica e teorização própria. Foram constituídos comissões e organismos de salvaguarda, elaboradas diretrizes metodológicas para intervenções práticas de conservação a partir de premissas teóricas delimitadas, realizados os primeiros registros e pesquisas documentais, e criadas legislações próprias. Inicialmente, este movimento se deu nos países europeus, e, posteriormente, serviram de modelo e foram aplicadas na maior parte dos países ao redor do globo, principalmente após a adoção da Convenção do Patrimônio Mundial ${ }^{12}$ (1972) pela UNESCO (Organização das Nações Unidas para a Educação, a Ciência e a Cultura).

Ao longo deste intervalo relativamente curto, a expansão do objeto patrimonial foi exponencial no número de bens inventariados, registrados, protegidos e preservados. Na Lista do Patrimônio Mundial, ratificada por 194 estados-membro, a totalidade dos países do mundo, figuram atualmente (2021) 1121 propriedades, das quais 869 culturais, 213 naturais e 39 mistas (tanto culturais quanto naturais). Os bens começaram a compor a lista em 1978, com 12 bens listados, sendo 8 culturais e 4 naturais, ao final da $2^{2}$ sessão do Comitê do Patrimônio Mundial. Na terceira sessão em 1979, 45 novos bens foram acrescentados à lista. Apenas no ano de 2000, 61 novas propriedades foram inscritas, um recorde histórico, de acordo com dados obtidos no portal da entidade. Este processo abrange até mesmo civilizações mais remotas, que, por questões culturais próprias, tinham até recentemente outra relação com seus bens patrimoniais. No entanto, diante das pressões e vantagens para participar destes organismos internacionais de salvaguarda e garantir a proteção de seu patrimônio cultural (muitas vezes considerado relevante para toda a humanidade, como os sítios históricos de grandes civilizações da humanidade), os países membros contam com benefícios que vão além do reconhecimento de seus tesouros culturais, que passam a figurar como relevantes atrativos turísticos - contam também com o acesso a auxílio financeiro para preservar e estruturar uma infraestrutura de salvaguarda de seu patrimônio.

\footnotetext{
${ }^{12}$ A Convenção para a Proteção do Patrimônio Mundial, Cultural e Natural é um compromisso internacional proposto na 17a Conferência Geral da UNESCO, realizada em Paris em novembro de 1972. Os dados citados acerca dos bens listados foram retirados do portal da Convenção do Patrimônio Mundial: https://whc.unesco.org/en/convention/. Acesso em junho de 2021.

\begin{tabular}{|l|l|l|l|l|}
\hline Q Rovista Dialectus & Ano 10 & n. 22 & Edição Especial, junho 2021 & p. 64- 83 \\
\hline
\end{tabular}
}


O patrimônio cultural, reconhecido como uma importante ferramenta de expressão e construção da identidade de uma dada sociedade e que atua como suporte da memória coletiva, revela, em suas próprias dinâmicas, problemáticas e questões complexas e desafiadoras. Entre elas, a relação desta sociedade com seus valores e epistemologia própria, com suas diversas narrativas históricas, com a natureza distinta de suas manifestações culturais, com a representatividade dos diferentes estratos e grupos sociais, com o valor que é atribuído ao seu patrimônio e de que maneira a sua preservação é feita. Em 1931, os países reunidos na primeira reunião internacional a respeito do patrimônio eram exclusivamente europeus, momento em que foi redigida a primeira Carta Patrimonial ${ }^{13}$. No segundo encontro, em 1964, eram três os países não-europeus: Tunísia, México e Peru (CHOAY, 2001). Em suma: somente muito recentemente os demais países aderiram à Convenção, que foi escrita a partir de princípios e experiências estritamente europeias. Estas diferenças culturais significativas na interpretação de valores levaram à realização de algumas assembleias com temáticas e discussões ricas em termos do confronto dos valores a partir desta diversidade, como é o caso da Conferência de Nara, realizada no Japão em 2004, em que se discutiu o conceito de autenticidade no patrimônio. Nos documentos internacionais que se estabeleceram ao longo do século XX, a autenticidade é considerada um dos principais fatores de atribuição de valor (Carta de Veneza, 1964). No entanto, a autenticidade aqui é interpretada à luz das concepções ocidentais de autenticidade material, sobretudo a matéria original. Em algumas culturas orientais e indígenas, a matéria é o que menos importa - os edifícios passam por procedimentos rituais de demolição e reconstrução periódica, e é nesta prática que reside a autenticidade, não na matéria, exigindo interpretações e abordagens distintas em cada contexto cultural (KÜHL, 2008).

Neste sentido, o patrimônio, conforme foi se constituindo até a metade do século XX, reflete os valores modernos da pretensão universalizante, sobretudo a partir das perspectivas eurocêntricas e coloniais. Isso se reflete, em específico, na constituição dos organismos internacionais de salvaguarda, que determinam uma espécie de "discurso autorizado" do que o patrimônio, sua função e o critérios para sua seleção, em detrimento de

\footnotetext{
${ }^{13}$ As Cartas Patrimoniais são documentos, redigidos ao final de eventos específicos, promovidos pelos órgãos internacionais ou nacionais de salvaguarda, que reúnem representantes dos países membros para debater conceitos e metodologias de preservação dos bens patrimoniais. Por se tratarem de compromissos internacionais, não constituem em documentos normativos, mas apenas orientações para a abordagem da temática e base para a o desenvolvimento de legislação e diretrizes locais próprias.
}

\begin{tabular}{|l|l|l|l|l|}
\hline Q Ronista Q Dialectus & Ano 10 & n. 22 & Edição Especial, junho 2021 & p. 64- 83 \\
\hline
\end{tabular}


um diálogo mais horizontalizado com as populações tradicionais que produzem e mantém vivos o patrimônio que se propõe proteger (SMITH, 2006).

\begin{abstract}
A história do patrimônio fica marcada pela monumentalização, pela celebração das civilizações e das identidades triunfantes nos processos de colonização e pela emergência de uma indústria patrimonial promovida pelos Estados hegemônicos e, mais tarde, pelas agências multilaterais (como, por exemplo, a Unesco, o Icomos e o Conselho da Europa). Este patrimônio, que resulta das forças motrizes da colonização levada a cabo pelos europeus, é também, e particularmente, filho de duas Guerras Mundiais, do sofrimento que elas causaram e da evidenciação do grau de exposição ao risco de desaparecimento súbito (PEIXOTO, 2007, p. 15).
\end{abstract}

Ao mesmo tempo em que estes organismos se estruturavam, ao longo do séc. XX, houve também um forte processo de descolonização - uma multiplicidade de países e culturas que, desprendidos do jugo de seus colonizadores, os quais imprimiram ao longo de séculos sua própria cultura como forma de dominação, passam também a retomar sua própria memória, sua história, sua identidade cultural e inventar suas tradições, em parte como fruto de um processo de autodescoberta e de construção da sua identidade cultural desvinculada do colonizador, criando os elos de coesão social através dos símbolos representativos próprios.

No caso específico do Brasil, o órgão responsável pela salvaguarda dos bens de valor nacional, o IPHAN ${ }^{14}$ (Instituto do Patrimônio Histórico e Artístico Nacional) e a primeira legislação específica de preservação do patrimônio brasileiro, o Decreto-Lei $\mathrm{n}^{\mathrm{0}}$ 25. foram criados em 1937. Desde então, ao longo de 84 anos de existência, o IPHAN

acautelou, via instrumento do tombamento, 1.241 bens materiais; via instrumento do cadastro, cerca de 24 mil sítios arqueológicos; e via instrumento do registro, quarenta bens imateriais (sem considerar as línguas inventariadas e os bens ferroviários valorados). Resultado da mais alta relevância para a cultura brasileira (SCHLEE e QUEIROZ, 2017, p. 118).

Inicialmente conduzidas pelos modernistas brasileiros, boa parte dos bens culturais brasileiros levantados e protegidos, sobretudo nas primeiras décadas de atuação do IPHAN, eram coloniais e buscavam constituir o que se entendia como arquitetura propriamente brasileira, de identidade nacional, desassociada das tendências construtivas europeias. São igrejas, centros históricos como Ouro Preto-MG (elevado à condição de monumento nacional em 1938), Casas de Câmara e Cadeias e outros edifícios da herança luso-brasileira. Restrito a uma visão que privilegiava o patrimônio material edificado (de "pedra e cal"), dentro de uma atribuição de valores estéticos e culturais bastante específica - rejeitando, por exemplo, os edifícios ecléticos construídos à moda europeia da segunda metade do século XIX em diante -

${ }^{14}$ No momento da sua fundação, o órgão era denominado SPHAN (Serviço do Patrimônio Histórico e Artístico Nacional), passando por diversas mudanças de nomenclatura ao longo da história.

\begin{tabular}{|l|l|l|l|l|}
\hline Q Rovista Dialectus & Ano 10 & n. 22 & Edição Especial, junho 2021 & p. 64- 83 \\
\hline
\end{tabular}


o IPHAN não tomou medidas significativas no intuito de documentar ou preservar, de alguma maneira, o legado indígena ou afro-brasileiro neste primeiro momento, apesar do vanguardismo do pensamento cultural expresso no projeto de lei de autoria de Mario de Andrade, que contemplava desde a cultura erudita à popular e indígena, além de manifestações culturais intangíveis, muito antes da consolidação desta categoria somente no início do próximo século (FONSECA, 2005). Calcadas principalmente nas tradições imateriais transmitidas de geração a geração por meio da oralidade, as manifestações culturais destes grupos minoritários só passaram a ser registradas adequadamente a partir da publicação do Decreto 3-551/2000, que define as políticas nacionais de preservação de bens culturais de natureza imaterial. Amparadas no entendimento da pluralidade cultural e numa abordagem mais antropológica do patrimônio que se constrói a partir da década de 1960, indígenas e quilombolas foram contemplados com proteção específica, sobretudo, a partir da Constituição de 1988.

No caso específico do patrimônio dos povos originários brasileiros, estas políticas precisam levar em conta uma série de particularidades conceituais, culturais e identitárias de cada uma das 305 etnias, tais como as suas concepções próprias de memória e história, suas práticas e processos de reconhecimento de seu patrimônio (CAPIBERIBE, 2020, pp. 229-230).

No caso do patrimônio afro-brasileiro, segundo Abreu e Monteiro,

\begin{abstract}
As culturas afro-brasileiras nem sempre foram consideradas patrimônios, muito menos patrimônios culturais do Brasil. Perseguidas historicamente ou vistas como folclore e vestígios de um passado que tendia a desaparecer pelas pressões da modernidade, só recentemente começaram a ser consideradas por especialistas da cultura e pelos próprios detentores como patrimônio (...) O reconhecimento público da existência de patrimônios culturais afro-brasileiros precisou vir acompanhado de uma mudança mais ampla de concepção do que é patrimônio no Brasil (ABREU e MONTEIRO, 2020).
\end{abstract}

Atualmente, várias expressões culturais afro-brasileiros são registrados como patrimônio imaterial, tais como o Ofício das Baianas do Acarajé, Ofício dos Mestres de Capoeira, o Bumba Meu Boi do Maranhão, e formas de expressão como o samba de roda, o maracatu e o samba carioca, entre outros (ABREU E MONTEIRO, 2020).

Além do silenciamento provocado pela exclusão de bens protegidos, uma problematização mais recente da questão chamou a atenção no âmbito das manifestações do Black Lives Matter, em 2020 (em protesto contra a morte violenta do americano George Floyd, por um policial branco). Em meio às manifestações antirracistas, diversas estátuas associadas com episódios históricos racistas ou coloniais foram derrubadas ou vandalizadas em diversos países. Nos Estados Unidos, estátuas e símbolos associados aos Confederados, exército dos

\begin{tabular}{|l|l|l|l|l|}
\hline Qevista Dialectus & Ano 10 & n. 22 & Edição Especial, junho 2021 & p. 64- 83 \\
\hline
\end{tabular}


estados sulistas contrário à abolição da escravidão na Guerra da Secessão americana, foram removidos do espaço público após pressão popular. Em Bristol, na Inglaterra, a estátua de Edward Colston, um traficante de escravos africanos que fez fortuna no século XVII foi derrubada e arremessada em um rio. Na Colômbia, em setembro de 2020, indígenas da etnia piurek derrubaram uma estátua em homenagem ao colonizador espanhol Sebastián de Belalcázar, após um julgamento simbólico dos seus crimes, que incluíam massacres e abusos contra indígenas e a apropriação de suas terras e heranças. Estes eventos, como diversos outros ocorridos anteriormente, representam a insurgência contra a celebração de uma narrativa histórica triunfalista que não é apenas excludente, mas violenta. Monumentos no espaço público são carregados de forte significado, da imposição de uma história oficial em que se tripudia populações oprimidas, subordinando sua presença. Neste sentido, a derrubada das estátuas não consiste em uma tentativa de apagamento de um fato histórico cristalizado, mas de uma ressignificação de sua posição nesta narrativa, uma tentativa de "descolonizar o patrimônio" (MENEZES NETO, 2020). Para o autor, a presença destas estátuas no espaço público são uma espécie de antipatrimônio, na medida em que acentuam as tensões sociais. Portanto "a derrubada parece ser a apropriação mais potente do conceito de patrimônio dos últimos tempos, uma apropriação crítica à maquinaria patrimonial, feita por aqueles que não a operam e que eram até então obrigados a acatar e preservar referências de violência" (MENEZES NETO, 2020, s/p).

A cisão entre a imagem idealizada e o objeto real, fruto de uma narrativa muitas vezes asséptica de um passado conflituoso, também se faz sentir no tratamento contemporâneo dos espaços e sítios culturais (HENNING, 2019). Em diversas abordagens frequentes, o bem patrimonial real, que se constitui e acumula marcas ao longo do seu transcurso pelo tempo, passa a ser sobreposto por um tratamento estilizado de sua imagem. São edifícios repristinados, pintados com cores vibrantes e lúdicas que não têm relação com sua natureza, ou modernizados com intervenções contemporâneas que não se subordinam às preexistências (KÜHL, 2008). A imagem se impõe como um simulacro do objeto, voltado ao consumo turístico hedonista. O edifício antigo atualizado em intervenções rejuvenescedoras, que remove a densidade do tempo, se congela em um presente eterno. Muitas vezes, tratado meramente como um cenário, o simulacro do patrimônio se transforma em um pano de fundo para atividades mais interessantes como performances artísticas e apresentações musicais ou folclóricas. Nestes espaços, a ênfase se retrai do caráter histórico-cultural dos edifícios e dos espaços, com suas complexidades, tensões e contradições, e se concentra na imagem atraente do destino turístico. Até mesmo as

\begin{tabular}{|c|c|c|c|c|}
\hline Qovista Dialectus & Ano 10 & n. 22 & Edição Especial, junho 2021 & p. $64-83$ \\
\hline
\end{tabular}


disputas sociais inerentes a uma sociedade desigual devem desaparecer. Nos bairros gentrificados, pessoas em situação de rua são afastadas por uma arquitetura hostil, comunidades marginalizadas são removidas (à força ou em decorrência do aumento do custo de vida nas regiões revitalizadas). Na imagem instagramável, não cabe retratar aquilo que possa causar uma experiência negativa no consumidor. Nestas localidades, comoditizado, tornado bem de consumo, espetacularizado, o patrimônio cultural se subordina à lógica do capital.

\section{Educação patrimonial e cidadania: reflexões à guisa de uma conclusão}

O patrimônio, moderno por natureza, surge no contexto das grandes narrativas históricas e na construção da identidade nacional. Desde sua origem, foi compreendido como algo que precisa ser ensinado, posto que seu valor precisa ser reconhecido a cada nova geração. Assim, na maior parte das Cartas Patrimoniais, como a Carta de Veneza (1964), se reitera a necessidade de realizar a educação patrimonial, difundindo à comunidade e às novas gerações a sua importância, para garantir a sua permanência. Os objetivos da educação patrimonial são, também, o de "formar sujeitos de sua própria história, que atuem na reivindicação de seus direitos coletivos e no fortalecimento da sua cidadania" (BEZERRA, 2020). A partir de uma perspectiva Freireana, que associa a educação com a cultura e a política, instigando a reflexão crítica e a consciência da coletividade, a educação patrimonial vem se consolidando desde a década de 1980 no Brasil em oficinas e atividades promovidas pelo IPHAN e organismos locais, como museus e centros culturais instalados nos sítios patrimoniais, que propõe a difusão de seu conteúdo.

No entanto, imerso na lógica cultural do capitalismo tardio (JAMESON, 1997), o patrimônio como espelho da sociedade, revela as profundas contradições da pós-modernidade. Por um lado, se coloca como uma manifestação coletiva, por outro, é sequestrada pela lógica do mercado, da propaganda e do marketing. Como questiona Harvey,

Terá [o pós-modernismo] um potencial revolucionário em virtude de sua oposição a todas as formas de metanarrativa (incluindo o marxismo, o freudismo e todas as modalidades de razão iluminista) e da sua estreita atenção a 'outros mundos' e 'outras vozes' que estavam silenciados (mulheres, gays, negros, povos colonizados com sua história própria)? Ou não passa da comercialização e da domesticação do modernismo e de uma redução das aspirações já prejudicadas deste a um ecletismo de mercado ‘vale tudo', marcado pelo laissez-faire?" (HARVEY, 2008, p. 47)

Por um lado, o patrimônio atua como suporte da memória e ferramenta para a construção da identidade e da consciência coletiva. Por outro lado, de quais memórias se tratam? Como lidar com as memórias difíceis, silenciadoras ou violentas? Os espaços de 
memória relacionados a episódios trágicos da nossa história, como campos de concentração nazistas ou monumentos dedicados aos mortos, que têm como princípio mobilizar continuamente as sensibilidades para que eventos como estes não se repitam, se veem esvaziados de sentido na era da imagem. Imagens de jovens em poses alegres, registrando suas visitas em selfies postadas nas redes sociais em locais que deveriam suscitar reflexões profundas ${ }^{15}$ apenas expõem o lado superficial e hedonista de uma sociedade profundamente individualista - e, ao mesmo tempo, indicam a importância da uma educação libertadora, crítica, que seja capaz de mergulhar na vivência para além da simples aparência do espetáculo. Enquanto o patrimônio for tratado como mero atrativo turístico ou bem de consumo, com sua imagem sanitizada e insistindo em reproduzir narrativas históricas e sociais totalizantes e excludente, a sua importantíssima função social e cultural não se realiza - ou se realiza pelo avesso: através do confronto e da iconoclastia. Neste caso, é preciso acolher e compreender as disputas sociais em jogo, para não insistir no silenciamento em nome de uma pretensa defesa dos monumentos controversos da história. Não precisamos, necessariamente, apagar as memórias conflitantes, mas confrontá-las e ressignificá-las. Os fatos históricos não mudam mas nossa interpretação destes fatos está em contínua elaboração. É preciso dar voz para os diferentes atores sociais e incluí-los no processo de produção de sentido, promovendo uma educação patrimonial reflexiva que não seja apenas passiva ou anedótica, mas uma construção de uma identidade coletiva e crítica.

A patrimonialização atual é uma certa forma de resistência, uma luta contra a obliteração completa em um contexto de mudanças profundas e aceleradas. O futuro promissor do início do século não produz mais uma sensação de promessa, mas de angústia. A sensação de que é necessário proteger rapidamente tanto a diversidade cultural quanto a biodiversidade, demonstram que o "futuro não é mais um horizonte luminoso para o qual marchamos, mas uma linha de sombra que colocamos em movimento em direção a nós, enquanto parecemos marcar passo no presente e ruminar um passado que não passa" (HARTOG, 2006, p. 273). Ao invés de se recolher à alienação do consumo e da busca do eterno presente fugaz, o patrimônio pode, através das reflexões que suscita, atuar como um bálsamo que acalmam nossas feridas. Afinal,

A especificidade do monumento deve-se precisamente ao seu modo de atuação sobre a memória (...) O monumento assegura, acalma, tranquiliza, conjurando o ser do

\footnotetext{
${ }^{15} \mathrm{O}$ artista israelense Shahak Shapira criou um projeto virtual denominado "Yolocaust" em que manipula as imagens de turistas em locais de memória do holocausto nazista, postadas nas redes sociais, contrapondo as poses e sorrisos com a ambiência da tragédia. O trabalho, junto com o manifesto do autor, pode ser visto em https://yolocaust.de/. Acesso em junho de 2021.
}

\begin{tabular}{|c|c|c|c|c|}
\hline Qovista Dialectus & Ano 10 & n. 22 & Edição Especial, junho 2021 & p. 64- 83 \\
\hline
\end{tabular}


tempo. Ele constitui uma garantia das origens e dissipa a inquietação gerada pela incerteza dos começos. Desafio à entropia, à ação dissolvente que o tempo exerce sobre todas as coisas naturais e artificiais, ele tenta combater a angústia da morte e do aniquilamento (CHOAY, 2001, p. 18). 


\section{Referências Bibliográficas:}

ABREU, Martha C.; MONTEIRO, Lívia N. Patrimônios afro-brasileiros. In: CARVALHO, Aline; MENEGUELLO, Cristina. Dicionário temático de patrimônio: debates contemporâneos. Campinas: Editora da Unicamp, 2020. Pp. 241-243.

BAUMAN, Zygmunt. O mal estar na pós-modernidade. Rio de Janeiro: Jorge Zahar, 1998.

Modernidade líquida. Rio de Janeiro: Jorge Zahar, 2001.

CAPIBERIBE, Artionka. Patrimônio Indígena. In: CARVALHO, Aline; MENEGUELLO, Cristina. Dicionário temático de patrimônio: debates contemporâneos. Campinas: Editora da Unicamp, 2020. Pp. 229-232.

CHOAY, Françoise. A Alegoria do Patrimônio. São Paulo: Estação Liberdade/Ed. Unesp, 2001.

DÉBORD, Guy. A Sociedade do Espetáculo. Rio de Janeiro: Editora Contraponto, 1997.

FONSECA, Maria Cecília F. L. Patrimônio em processo: trajetória da política federal de preservação no Brasil. Rio de Janeiro: Editora UFRJ; MinC-IPHAN, 2005.

FRAMPTON, Kenneth. Modern Architecture: a critical history. Nova York: Thames \& Hudson, 2004.

GALLO, Silvio. Modernidade/pós-modernidade: tensões e repercussões na produção de conhecimento em educação. In: Educação e Pesquisa, São Paulo, v.32, n.3, p. 551-565, set./dez. 2006.

HARTOG, François. Regimes de Historicidade - presentismo e experiências do tempo. Belo Horizonte: Autêntica Editora, 2014.

HARVEY, David. A condição pós-moderna. São Paulo: Edições Loyola, 2008.

HENNING, Priscila. O espetáculo do patrimônio: imagem e turismo no centro histórico de São Francisco do Sul - SC. 2019. 351 f. Tese (Doutorado em História) - Instituto de Filosofia e Ciências Humanas, Universidade Estadual de Campinas, Campinas, 2019

JACQUES, Paola Berenstein. Patrimônio cultural urbano: espetáculo contemporâneo? In: Revista de Urbanismo e Arquitetura, Salvador, vol. 6, no 1, 2003, p. 33-39. Disponível em: http://www.portalseer.ufba.br/index.php/rua/article/view/3229/2347. Acesso em junho de 2021.

JAMESON, Fredric. Pós-Modernidade: A lógica cultural do capitalismo tardio. São Paulo: Ed. Ática, 1997.

KÜHL, Beatriz Mugayar. Preservação do Patrimônio Arquitetônico da Industrialização: Problemas teóricos de restauro. Cotia: Ateliê Editorial, 2008.

LIPOVETSKY, Gilles. Os tempos hipermodernos. São Paulo: Barcarolla, 2004.

LYOTARD, Jean-François. A condição pós-moderna. Rio de Janeiro: José Olympio, 2009.

MENEZES NETO, Hugo. Notas sobre patrimônio, estátuas derrubadas e vidas precarizadas. In: Revista Aurora - Revista da Semana do Patrimônio Cultural do Pernambuco. Recife, FUNDARPE, v. 1, n. 5, 2020, pp. 55-65.

\begin{tabular}{|c|c|c|c|c|}
\hline Qovista Dialectus & Ano 10 & n. 22 & Edição Especial, junho 2021 & p. 64- 83 \\
\hline
\end{tabular}


PEIXOTO, Paulo. Tudo o que é sólido se sublima no ar: políticas públicas e gestão do patrimônio. In: CYMBALISTA, Renato; FELDMAN, Sarah; KÜHL, Beatriz. Patrimônio cultural: memórias e intervenções urbanas. São Paulo: Annablume/Núcleo de Apoio e Pesquisa São Paulo, 2017.

RODRIGUES, Marly. Políticas públicas e patrimônio cultural. In: CARVALHO, Aline; MENEGUELLO, Cristina. Dicionário temático de patrimônio: debates contemporâneos. Campinas: Editora da Unicamp, 2020. p. 87-90.

SCHLEE, Andrey R; QUEIROZ, Hermano. O jogo de olhares. In: Revista do Patrimônio Histórico e Artístico Nacional. No 35. IPHAN, 2017. pp. 105-120.

SMITH, Laurajane. Uses of Heritage. New York: Routledge, 2006.

URRY, John. Globalizando o olhar do turista. In: PLURAL, Revista do Programa de Pós-Graduação em Sociologia da USP, São Paulo, 2016, v.23.2, p.142-155. 